\title{
Sobre a classificação gradual das preposições
}

\author{
On the gradual classification of prepositions
}

\author{
Lou-Ann Kleppa \\ Universidade Federal de Rondônia
}

\begin{abstract}
The present paper is set in the field of discourse-oriented Neurolinguistics. A gradual classification of prepositions (in contrast with the traditional categorical ones) offered interesting possibilities when describing the behaviour of prepositions in the speech of subjects with a heterogeneous language. In these cases, the currently available classifications of prepositions were not considered adequate. The reasons why another classification (in which the prepositions are put on a scale according to their degrees of grammaticalization) is preferred will be given after a review of the works published on categories of prepositions. Classifications suggested by grammarians and neurolinguists concerned with describing the agrammatical speech of subjects with production aphasia will be examined in order to defend a gradual classification of prepositions.
\end{abstract}

Keywords

Prepositions, Classification, Degrees of grammaticalization, Agrammatism. 


\section{Resumo}

O presente artigo está ancorado na Neurolinguística de orientação enunciativo-discursiva. A demanda por uma proposta de classificação gradual (em oposição à tradicional classificação categorial) das preposições surgiu quando nos propusemos a tarefa de descrever o funcionamento das preposições na fala de sujeitos que apresentam uma linguagem heterogênea. Nestes casos, as classificações correntes das preposições não se mostraram satisfatórias. Os motivos pelos quais preferimos uma classificação que dispõe as preposições numa escala de acordo com os seus graus de gramaticalização serão dispostos depois de feita uma revisão da literatura sobre as classificações das preposições. As classificações propostas por diferentes gramáticos são analisadas juntamente com aquelas adotadas por linguistas preocupados em descrever a linguagem agramática de sujeitos com afasia de produção.

\section{Palavras-chave}

Preposições, Classificação, Graus de gramaticalização, Agramatismo. 


\section{Introdução}

$\mathrm{O}$

termo português preposição tem origem latina: prae positio, ou praepositione, que significa "posicionar à frente". Em português, este termo é adequado, dado que todos os elementos que compõem esta classe de palavras são posicionados à frente de sintagmas preposicionais. Contudo, nem todas as línguas possuem elementos relacionais que se posicionam à esquerda de núcleos de sintagmas preposicionais, mas à sua direita. Estas são chamadas de posposições; existentes, por exemplo, em hindi, húngaro, coreano e línguas da família balto-fínica. Existem ainda línguas como alemão que apresentam, além de preposições e algumas posposições, raras circumposições ${ }^{1}$ (em volta do argumento). O hiperônimo para todos estes termos (preposições, posposições e circumposições) é aposição. Aposições são elementos relacionais que desempenham um papel sintático (são tomadas como indicadores de regência do verbo sobre seus argumentos, por exemplo) e semântico (expressam, por exemplo, relações de espaço, tempo, modo/ noção) na sentença.

A classificação das preposições é uma questão importante para estudos sobre preposições na fala de sujeitos com a fala heterogênea, como é o caso, por exemplo, de sujeitos afásicos com agramatismo. Na literatura consultada, as formas de classificar as preposições identificadas na fala de sujeitos com agramatismo são várias, mas são todas de natureza categorial (ou tudo ou nada, ou lexical ou gramatical). O presente artigo pretende defender uma classificação gradual das preposições identificadas na fala de dois sujeitos agramáticos. As preposições são dispostas numa escala, de acordo com o seu grau de gramaticalização.

Na última década, o fenômeno da gramaticalização tem recebido atenção de pesquisadores brasileiros, mas ainda há poucos trabalhos publicados sobre a gramaticalização das preposições sob o ponto de vista sincrônico. A seguir, a Hipótese da Gramaticalização será apresentada e a gramaticalização das preposições de, em, para, a, com, por, até, desde, entre, sem, contra e 
sobre será discutida. A classificação gradual das preposições será contrastada com os tipos de classificação categorial encontrados nas gramáticas, Linguística em geral e Neurolinguística em específico.

\section{Processos de gramaticalização}

Não há apenas uma única definição para o fenômeno da gramaticalização, e no Brasil os estudos que adotam esse enfoque estão crescendo (podemos citar os trabalhos de POGGIO, 2000, 2002; LONGHIM, 2003; KLEPPA, 2005, 2008a, b; GONÇALVES et al., 2007 e ILARI et al, 2009). Certo está que é um fenômeno observável diacronicamente. Dahl (2001), fazendo uma breve resenha sobre a história do termo gramaticalização, refere-se a Meillet $(1912)^{2}$ como sendo o primeiro a usar o termo. Na acepção de Meillet, a gramaticalização é o processo em que elementos lexicais sofrem alterações de tal modo que se tornam elementos gramaticais. Essa noção foi estendida por Hopper \& Traugott (1993) de modo que, segundo esses autores, itens lexicais ou construções lexicais passam a assumir funções gramaticais em certos contextos. Squartini (1998, p. 1) esquematiza a evolução do processo que a unidade lexical sofre:

Item lexical usado em contextos específicos > sintaxe > morfologia.

Com base nesse esquema, podemos inferir que uma unidade lexical que é submetida ao processo de gramaticalização tende a assumir uma posição fixa na sentença; e, se o processo de gramaticalização continuar, essa unidade transforma-se em morfema que é aglutinado a uma unidade lexical, sofrendo perda fonética ou não. Segundo Squartini (1998), a teoria atual sobre a gramaticalização assume que estas vias (paths) de gramaticalização não podem ser revertidas, ou seja, o processo é unidirecional. Haspelmath (1999), Hopper \& Traugott (1993) e Di Meola (2002), entre outros, sustentam a unidirecionalidade do processo de gramaticalização. Há ainda outros autores, como Gabelentz (1891), ${ }^{3}$ que usam a metáfora da espiral para descrever a evolução do processo de mudança de itens lexicais para gramaticais. Geurts (2000) ${ }^{4}$ e mais recentemente Dahl (2001) assumem que o processo de gramaticalização seja um processo cíclico.

A gramaticalização é um fenômeno que pode envolver a criação de parâmetros para novos tempos verbais - esse é o caso da formação do futuro em português: 
amare habeo $>$ amare aio $>$ amarei

Uma vez que essas estratégias são consolidadas, tornam-se um paradigma produtivo na língua. É interessante notar que o processo de gramaticalização não está completo no exemplo acima, já que é possível destacar a marca de futuro e deslocá-la, o que dá provas de que não se está diante de um morfema preso strtictu sensu:

hei de amar e amá-lo-ei

Gramaticalização implica, além de mudança de categoria, uma mudança semântica. Fica em aberto a questão da existência de uma determinação hierárquica no processo de gramaticalização, ou seja, se o esvaziamento semântico determina o enriquecimento funcional ou vice-versa. Os autores pesquisados constatam apenas um esvaziamento/ desbotamento semântico em itens gramaticalizados. O esvaziamento, porém, não é completo: mesmo na função de item gramatical, o elemento gramaticalizado ainda retém um conteúdo semântico que pode ser retraçado até o item lexical de origem. Há diferentes níveis de gramaticalização, implicando diferentes graus de saliência semântica. Bybee \& Pagliuca (1987) ${ }^{5}$ e Bybee \& Perkins \& Pagliuca (1994) ${ }^{6}$ insistem que mesmo um morfema altamente gramaticalizado retém, de alguma forma, o conteúdo semântico do item lexical de origem. Um exemplo de gramaticalização citado em Squartini (1998) é o de marcadores de aspecto que emergem de marcadores de acionalidade. Outro exemplo é a marcação de advérbio -mente, que, numa perspectiva diacrônica, foi um lexema independente:

Siegfried lutou com a mente corajosa > Siegfried lutou corajosamente.

É de se notar que o valor semântico da palavra mente não é mais aparente quando se tem um advérbio terminado em - mente. Quando, porém, atentamos para a forma desse sufixo, é possível identificar um vestígio do item lexical de origem: o adjetivo que admite o sufixo -mente carrega a marca de gênero feminino, (corajosamente, não corajosomente, ou ainda friamente, não friomente), remetendo ao gênero da palavra mente. Podemos dizer então que o item lexical mente tomou dois "caminhos" no decorrer do tempo: em um caminho o item continua significando o mesmo que já significava em latim; no outro, o item assumiu um lugar fixo na sentença, seu valor semântico foi 
esvaziando-se, a frequência do uso do item naquela posição aumentou e o elemento aglutinou-se a outro item lexical, passando a funcionar como morfema indicador da classe de advérbios, sem que o item gramaticalizado sofresse perda fonética. Atingido este status, o sufixo pode ser usado para formar novos advérbios: Selma se veste feiamente ou ainda Samuel escreve obscuramente.

Não é necessário, todavia, que a evolução esteja completada, para que se possa tratar de fenômenos de gramaticalização. Basta que um termo lexical tenha, do ponto de vista diacrônico, assumido uma posição fixa na sentença, sofrido uma mudança categorial, e sofrido um esvaziamento semântico, para que se possa tratá-lo como resultado de um processo de gramaticalização. Uma abordagem diacrônica das preposições do português brasileiro, como a encontrada em Brandão (1963), revelará que as preposições são resultado de um processo de gramaticalização:

As preposições indo-européias se originaram de certas partículas de caráter adverbial, assim como de adjetivos e particípios adverbializados e até mesmo de substantivos em função de advérbios. (...) Eis porque, em alguns idiomas, nem sempre aparecem assaz demarcadas as raias entre o advérbio e a preposição. (BRANDÃO, 1963, p. 540)

(...) Na origem, guardavam aquelas partículas sentido próprio e pleno, apondo-se a outros elementos fraseais, sem estarem adstritas a jungir-se intimamente quer com o verbo, quer com o nome que determinavam. O sânscrito, o dialeto homérico e até mesmo o latim oferecem espécimens dessa primitiva colocação livre. Com o volver do tempo, porém, tais partículas tenderam a grupar-se com um verbo, ou com um nome-complemento, pôsto em determinado caso, tornando-se inseparáveis dêles. A posição da partícula, a princípio livre, fixou-se então antes do verbo ou antes do seu complemento. No primeiro caso constituíram-se os prevébios (preposições em composição verbal ou prefixos). No segundo caso, transformaramse em preposições propriamente ditas, as quais, enfraquecido e às vezes obliterado o seu valor adverbial originário, adquiriram a função meramente relacional e passaram assim a conectivos intervocabulares. A determinação contida no prevérbio com freqüência se atenuava, tornava-se vaga, e, para reavivar-se a relação por êle expressa, 
fazia-se mister repeti-lo a ele ou uma preposição sinônima com êste ou aquêle caso, por exemplo em latim, com o acusativo e o ablativo, quando havia idéia de movimento ou de lugar onde real ou figurado: INscribere nomen IN tabula = inscrever o nome numa lista. (BRANDÃO, 1963, p. 541, grifos originais).

O gramático aponta para o que hoje chamamos de processo de gramaticalização: um item lexical (com sentido próprio e pleno) assume uma posição fixa na sentença (antes do verbo ou do complemento). Os elementos que se fixaram ao verbo transformaram-se em seus morfemas (explicar, complicar, implicar). Curioso é o que aconteceu a alguns prevérbios, que têm sua preposição sinônima ao prefixo: conversar com, introduzir em, etc. Estas preposições foram selecionadas pelos verbos porque o valor semântico do prefixo do verbo, que era uma preposição, foi sendo gradualmente esvaziado. Poggio (2000) dá a entender que o processo de gramaticalização das preposições já foi iniciado em latim:

Vale ressaltar que, mesmo as preposições gramaticalizadas no latim, continuam seu processo de gramaticalização no português, o que se evidencia, na maioria das vezes, através das freqüentes mudanças semânticas. (POGGIO, 2000, p. 397).

O processo de gramaticalização não se deu, contudo, da mesma forma para todas as preposições do português brasileiro, o que significa que podemos dispô-las em diferentes graus de gramaticalização. Em outras palavras, a classe das preposições do português brasileiro não é uma classe homogênea. Nesta classe coexistem elementos que podem ser amalgamados com outros itens linguísticos e outros que são invariáveis; há contextos em que as preposições que podem ser amalgamadas devem ser amalgamadas com outros itens linguísticos, senão a sentença torna-se agramatical. Coexistem também elementos com um grau elevado de saliência semântica e outros com um baixo grau de saliência semântica. Esses graus correspondem a níveis de gramaticalização.

Lehmann (1985) trata da escala de gramaticalização para diferenciar graus de gramaticalização sob a perspectiva sincrônica. Para estabelecer essa escala, usa o critério da autonomia do signo linguístico. Quanto menos autônomo, mais gramaticalizado está o item, ou seja, mais dependente ele é de 
outros elementos. Contudo, o autor não dispõe as preposições (da língua alemã ou inglesa) em sua escala.

Transpondo o princípio da autonomia do signo, podemos assumir que quanto mais diluído for o conteúdo semântico de uma preposição, mais dependente ela se torna do conteúdo semântico do termo que a seleciona. Com um conteúdo semântico esvaziado, ela poderá ocorrer em vários contextos sintáticos, já que seu valor semântico não é restrito ou específico, mas emerge em combinação com outros termos. Quanto maior for sua distribuição sintática, mais frequente ela será na língua. Quanto menos autônoma e mais frequente, mais gramaticalizada ela está. A cada preposição é atribuído um grau de gramaticalização em relação às outras, dispostas numa escala. Os critérios que estabelecem os graus de gramaticalização das preposições são:

(i) sua frequência na língua;

(ii) a possibilidade de amalgamar-se com outro item linguístico;

(iii) seu valor semântico;

(iv) sua distribuição sintática.

Poggio (2002) ressalta a questão da frequência:

Embora esse processo [de gramaticalização] seja o resultado da ação decorrente de vários fenômenos correlacionados, a freqüência de uso é o único fator que leva à gramaticalização, à regularização e à fixação.

Quanto mais a forma for gramaticalizada, mais ela será freqüente. Portanto, a freqüência de um item é evidência empírica de seu grau de gramaticalização. (POGGIO, 2002, p. 74-75).

Resumindo os resultados de Kleppa (2005), as preposições mais gramaticalizadas são muito frequentes, podem ser contraídas com outros itens linguísticos, assumem mais de um valor semântico, e introduzem tanto argumentos como adjuntos, enquanto as preposições menos gramaticalizadas são menos frequentes, sempre mantêm a sua forma, possuem um valor semântico específico e são apenas introdutoras de adjuntos.

Conforme descritas em Ilari et al. (2009, p. 647) e Kleppa (2005, 2008a, b), as seguintes preposições são consideradas mais gramaticalizadas: $\mathbf{d e}>\mathbf{e m}>$ para, a $>$ com $>$ por. Não há um consenso em relação ao grau de 
gramaticalização das preposições menos gramaticalizadas, mas o grupo das preposições menos gramaticalizadas é formado por: até, desde, sem, entre, contra e sobre. Mesmo incompleta, essa classificação gradual das preposições se mostra vantajosa na descrição das preposições identificadas na fala de sujeitos afásicos com agramatismo.

Apresentada a classificação gradual das preposições, passemos às classificações categoriais das preposições, para que possamos comparar métodos e critérios.

\section{Tipos de classificação categorial das preposições}

É comum que a classe de palavras ‘preposição’ não seja tratada de forma homogênea. Quando as preposições são descritas, seja por gramáticos, linguistas em geral ou neurolinguistas, costumam ser alocadas numa categoria (lexical ou gramatical) que pode ser subdividida em grupos menores. Estes grupos, no entanto, são estanques, e a escolha das categorias das preposições é feita com base em critérios semânticos, sintáticos e morfológicos. Como apenas um critério é usado para subdividir as preposições, as subdivisões são numerosas.

\subsection{Classificação de preposições nas gramáticas}

As gramáticas descritivas e prescritivas do português não seguem os mesmos critérios para classificar as preposições. ${ }^{7}$ De fato, as preposições podem ser descritas em vários níveis: fonético, morfológico, semântico, sintático e discursivo.

Se um gramático atentar para a forma das preposições, poderá subdividilas em simples e complexas, como o fazem Cunha (1979) e Vilela \& Koch (2001). É comum ainda que se note a variabilidade da preposição: Stolz (1990) defende que a preposição seja flexionável, alguns gramáticos dizem que ela é invariável, mas apresentam formas de combinação e contração de preposições e então abordam aspectos fonéticos das preposições.

No campo semântico, quase todos os gramáticos concordam que a preposição é um elemento relacional sem valor semântico próprio, mas que seu valor semântico emerge quando combinada com certos sintagmas. O único gramático que atenta para a diferenciação semântica das preposições é Lima (1998), quando distingue preposições fortes de fracas: 
Dividem-se as preposições em fortes e fracas. As primeiras (contra, entre, sobre) guardam certa significação em si mesmas; as outras $(a, c o m, d e)$ não têm sentido nenhum, expressando tãosomente, em estado potencial e de forma indeterminada, um sentimento de relação.

No contexto é que se concretiza o valor significativo das várias relações que elas têm aptidão para exprimir. (LIMA, 1998, p. 355 e 356, grifos originais).

Quanto ao plano sintático, alguns autores dividem as preposições em dois grupos: essenciais e acidentais, como o fazem Bechara (1967), Cegalla (1998), Lima (1998) e Neves (2000). Esta última autora subdivide ainda as preposições essenciais em potenciais introdutoras de argumentos e não introdutoras de argumentos. Por fim, observamos que as preposições são raramente descritas no plano discursivo. Uma primeira tentativa foi arriscada em Kleppa (2005).

\subsection{Classificação das preposições na Linguística}

A discussão sobre o estatuto categorial da preposição (tomando a classe das preposições como um todo) é frequente na bibliografia consultada, e pudemos notar que há, pelo menos, três vias principais:

- Autores ligados à teoria da Gramática Gerativa (RAPOSO, 1993; EMONDS, 1993) consideram que a preposição seja um item lexical, já que pode "encabeçar" um sintagma preposicional, assumindo o status de núcleo. Além deles, há vários outros autores que assumem uma posição lexicalista quando descrevem os aspectos semânticos das preposições (JESPERSEN, 1924; MEISEL, 1973; LARSON, 1987; BORSLEY; JAWORSKA, 1989; WUNDERLICH, 1991; CORMACK; BREHENEY, 1994).

- Há outros autores que assumem que a preposição seja um elemento gramatical (OUHALLA, 1993; SILVA, 1999 e todos os gramáticos consultados: ABREU; MOURA, 1957; ALMEIDA, 1969; AZEVEDO FILHO, 1966; BECHARA, 1967, 1999; BRANDÃO, 1963; CEGALLA, 1998; COUTINHO, 1979; CUNHA, 1970, 1979; GÓIS, 1957; LIMA, 1998; LUFT, 1985; MELO, 1970; NASCENTES, 1960; NEVES, 2000; SAMPAIO, 1953; SAVIOLI, 1991; SOUZA LIMA, 1937; TÔRRES, 1963 e VILELA; KOCH, 2001). 
- Há, por último, aqueles que discutem esta distinção entre categorias lexicais e gramaticais, sugerindo que a classe das preposições, se tomada como um todo, não é nem lexical nem gramatical, pois seus elementos se dispõem num continuum de dois polos: um lexical e outro gramatical (BAUDUSCH, 1984; RAUH, 1990, 1993, 2002; STENZEL, 1996; ZWARTS, 1997; HUDSON, 1997 e BERG, 1998). Nenhum desses autores, no entanto, adota a Hipótese da Gramaticalização para analisar as preposições. Trabalhos em que as preposições são dispostas num continuum de gramaticalização são, até onde temos notícia, de Ilari et al. (2009), Kleppa (2005; 2008a, b) e Poggio (2002).

\subsection{Classificação das preposições na Neurolinguística}

A separação entre preposições funcionais e lexicais é corriqueira na literatura, mas encontra sua aplicação prática mais pronunciada nos estudos de afasia, mais especificamente sobre o agramatismo. Tradicionalmente, o agramatismo é caracterizado como uma fala não fluente, em que

- são omitidas palavras funcionais (preposições, pronomes, conjunções, artigos),

- aparecem poucos verbos e

- há problemas com a ordem das palavras.

Note-se que apenas a organização sintática é estudada nesta abordagem que identifica déficits (por isso a ênfase na alteração da sintaxe, expressa no termo a-gramatismo).

Com base na observação de que nem todas as preposições estão ausentes da fala de sujeitos agramáticos, e no intuito de comprovar a hipótese disseminada de que os elementos funcionais (mas não os lexicais) estão ausentes da fala de sujeitos com agramatismo, alguns autores postulam uma subdivisão na classe das preposições. Assim, autores como Friederici $(1982,1985)$ e Friederici et al. (1982) classificam-nas como lexicais e obrigatórias. Grodzinsky (1988), Tesak \& Dittmann (1991), Tesak (1994) e Bastiaanse (1995) classificam-nas como governed e ungoverned. Nespoulous et al. (1988) classificam-nas como lexicais e não lexicais. Lonzi \& Luzzatti (1995) separam locativas de obrigatórias, e Guindaste (1996) divide as preposições em lexicais e funcionais. Desta maneira, assume-se que as preposições possam ser selecionadas ora 
semanticamente (quando, por exemplo, introduzirem adjuntos do verbo: de noite, de Pindamonhangaba, de bicicleta) ora sintaticamente (quando, por exemplo, introduzirem argumentos ou complementos do verbo: cuida de crianças, do substantivo: dependência de chocolate, ou do adjetivo: fácil de esquecer). Assim, um mesmo elemento (de, nos exemplos) pode ser 'lexical' num contexto e 'funcional' em outro.

Partindo da assunção de que a fala de sujeitos afásicos é um sintoma da lesão cerebral (e, mais radicalmente, uma janela direta para a organização e armazenamento da linguagem no cérebro), muitos autores usaram classificações de preposições como as elencadas anteriormente para descrever quais preposições estariam 'preservadas' na fala agramática e quais estariam 'prejudicadas'; quando são omitidas e quando são substituídas. De uma maneira geral, é defendido que, quando as preposições forem unidades morfologicamente independentes, as preposições lexicais (ou locativas ou ainda não governadas) estão "preservadas” na fala agramática, ao passo que as obrigatórias (ou funcionais, não lexicais ou ainda governadas) são “omitidas” na fala agramática. Ainda há estudos que afirmam que, quando amalgamadas a outros itens linguísticos, as preposições são mais facilmente substituídas (ver FRIEDERICI et al., 1992; HALLIWELL, 2000; MENN; OBLER, 1990; NILLIPOUR, 2000).

\section{Contrastando categorias e gradações}

Uma análise puramente sintática das preposições não possibilita o exame fonético, morfológico, semântico e discursivo da preposição. Escapa a uma análise sintática o fato de que há, em português, preposições invariáveis e preposições que podem ser amalgamadas a outros itens linguísticos. Essa propriedade da preposição pode ser associada à frequência e distribuição de cada preposição na língua. Se a essa conclusão forem acrescentadas observações no plano do comportamento semântico da preposição, os diferentes planos de análise podem ser unidos num conceito: gramaticalização.

A vantagem de adotar uma classificação gradual das preposições é que essa classificação mobiliza vários critérios linguísticos simultaneamente, permitindo uma visão panorâmica da classe das preposições. A desvantagem das classificações categoriais é que cada uma segue um único critério, portanto as classificações são numerosas. Nas gramáticas, por exemplo, as preposições são 
tratadas como itens gramaticais. Contudo, cada autor propõe subdivisões diversas, de acordo com a morfologia, valor semântico e distribuição das preposições. A frequência de uso das preposições não é levada em consideração nessas subdivisões, sendo que este é um critério relevante para sujeitos em processo de reconstrução da linguagem.

Outra vantagem de trabalhar com uma classificação gradual das preposições é que as preposições (enquanto realização material) são mapeadas, não as funções que elas exercem. Lembrando a seção anterior, numa perspectiva que separa as preposições funcionais das lexicais, uma mesma preposição pode exercer os dois papéis. Trocando em miúdos, um mesmo número de preposições 'de' identificadas num corpus pode ser recortado de duas maneiras: ou todas formam um grupo (as mais gramaticalizadas), ou são separadas em dois grupos (de funcionais e lexicais).

Dependendo das teorias adotadas para descrever a fala agramática, outros métodos serão adotados, de maneira que se chegará a resultados diferentes. Cada teorização sobre a fala agramática implica uma compreensão peculiar de língua e de sujeito na língua. Por exemplo, mapear a realização (ou não) das preposições é uma atividade relacionada à tentativa do pesquisador de modelar o armazenamento e funcionamento da linguagem no cérebro humano. Nesse sentido, o método de contabilizar 'omissões' e ‘substituições’ de preposições na fala de sujeitos agramáticos indica que o pesquisador atribui ao sujeito cérebrolesado comportamentos não naturais, complexos e que demandam tempo.

Outras abordagens teóricas, em que o mapeamento da 'língua no cérebro' não é o objetivo principal, são possíveis. É possível, por exemplo, investigar o material linguístico que determinado sujeito afásico produz e qual é a relação do que ele diz com a sua própria trajetória na língua e com o grau de exposição a situações de diálogo. Enfim, para abordagens de orientação enunciativodiscursiva, é interessante investigar como o sujeito agramático se adapta linguisticamente à sua condição afásica. Numa perspectiva como essa, questões de uso de linguagem (por exemplo, a frequência e distribuição das palavras na língua) são cruciais. Além do mais, a hierarquização das preposições na língua pode ser verificada grosso modo em termos quantitativos na fala de sujeitos agramáticos (aparecem em maior número as preposições mais gramaticalizadas). 


\section{Aplicando a classificação gradual das preposições no exame da fala de dois sujeitos agramáticos}

Resultados de Kleppa (2008b) mostram que dois sujeitos afásicos com agramatismo (MS e OJ) usam um número expressivamente maior de preposições mais gramaticalizadas em sua fala (tanto em conversas espontâneas como em situações experimentais). Segue um breve histórico de cada sujeito.

MS foi vítima de um AVC isquêmico em 2002 e tinha 60 anos quando foi entrevistado pela primeira vez (quatro anos post-onset). Tomando como referência o momento em que foi entrevistado pela primeira vez, participava das atividades do Centro de Convivência de Afásicos (CCA) situado na Unicamp fazia dois anos. MS apresenta 'fala telegráfica' e anomia, além de hemiplegia à direita. A maioria dos empregos que teve antes do derrame eram fortemente ligados à produção de linguagem: trabalhou como ator de teatro, professor de inglês em cursinho preparatório para o Vestibular, diretor de um programa televisivo, guia turístico no Paraguai e jornalista no Reino Unido. É graduado em Letras e lê frequentemente. MS não gosta de sua grafia (era destro e escreve com a mão esquerda desde o AVC) e passou a usar o computador (desde então) para escrever. Ele tem consciência de suas dificuldades de linguagem e demonstra uma atitude positiva em relação a elas: gosta de interagir através da linguagem, usa gestos, entonação, música e expressões corporais (não só faciais) em vez de palavras, encanta-se com as palavras (predominantemente nomes de cores e animais) de outras línguas (inglês e francês) que lhe vêm à boca nos experimentos e quer uma explicação para o fenômeno.

OJ tinha 55 anos quando foi entrevistado pela primeira vez ( 13 anos postonset) e tinha sido vítima de um AVC isquêmico em 1993. Segundo ele, não falou uma palavra durante os primeiros seis anos após o episódio neurológico, e apenas produzia 'pápápá'. Ele apresenta ‘fala telegráfica’ e anomia, além de hemiplegia à direita. OJ havia recentemente iniciado sua participação nas atividades do CCA, portanto ainda não estava familiarizado com o local ou as pessoas que nele trabalham. Antes do derrame, OJ trabalhava como vendedor de peças de televisão para lojas especializadas. Diferentemente de MS, OJ não teve ensino superior, tem dificuldade para ler (mal distingue letras isoladas) e escrever e apenas fala português. OJ julga ter problemas de memória, não de linguagem. Quando lhe falta uma palavra, frequentemente aponta para a têmpora e diz: cabeça, cabeça ou memória. Em vários momentos OJ diz que resolve situações 
(como se perder em algum lugar) conversando, conversando, conversando.

Os dois sujeitos foram gravados por períodos de tempo semelhantes (totalizando aproximadamente três horas gravadas), em situações dialógicas similares: uma sessão de conversa espontânea e várias sessões em que foram realizados experimentos para elicitar preposições. Esses experimentos eram jogos (de montar frases com cartões, de formar frases a partir de verbos, de identificar figuras semelhantes, de identificar rotas e lugares num mapa, de identificar sentenças gramaticalmente mal formadas, de completar provérbios). Foi coletado um volume maior de material linguístico produzido em situações de experimento do que de fala espontânea, mas isso não significa que a fala de MS e OJ tenha sido direcionada. Num jogo similar ao dos sete erros, por exemplo, preposições locativas eram esperadas, mas não havia previsão de quais preposições apareceriam, já que todas as preposições, exceto sem, se prestam a descrever relações espaciais.

Quando comparamos as preposições enunciadas por MS e OJ em situações de fala espontânea e de experimento, podemos constatar que os sujeitos

(i) usam as mais gramaticalizadas com maior frequência;

(ii) tendem a usar o mesmo repertório de preposições nas duas situações de fala.

Essa observação nos leva a concluir que as preposições não estão perdidas na fala dos sujeitos agramáticos, e que eles não são negativamente sensíveis a palavras funcionais (apagando-as de sua fala), mas positivamente sensíveis a palavras de alta frequência na língua (usando, assim, preposições mais gramaticalizadas). A Tabela 1 foi adaptada de Kleppa (2008b, p. 147): 
TABELA 1

Frequência das preposições na fala espontânea e evocada de MS e OJ.

\begin{tabular}{lcccc}
\hline & \multicolumn{2}{c}{ Fala espontânea } & \multicolumn{2}{c}{ Todos os experimentos } \\
\hline & MS & OJ & MS & OJ \\
\hline em & $\mathbf{4}$ & $\mathbf{4}$ & $\mathbf{1 6}$ & $\mathbf{5}$ \\
a & & $\mathbf{9}$ & $\mathbf{7}$ & $\mathbf{1 9}$ \\
com & $\mathbf{6}$ & & $\mathbf{1 9}$ & \\
de & $\mathbf{9}$ & $\mathbf{5}$ & $\mathbf{8}$ & \\
para & $\mathbf{2}$ & & $\mathbf{5}$ & $\mathbf{1}$ \\
sem & $\mathbf{1}$ & & $\mathbf{2}$ & \\
por & & & $\mathbf{2}$ & \\
contra & $\mathbf{1}$ & & $\mathbf{1}$ & \\
sobre & & & $\mathbf{1}$ &
\end{tabular}

Resumindo, em todo o corpus analisado, foram identificadas 78 preposições mais gramaticalizadas contra 6 menos gramaticalizadas na fala de MS e 43 preposições mais gramaticalizadas e nenhuma menos gramaticalizada na fala de OJ.

\section{Considerações finais}

Há autores que procuram definir as preposições como integrantes da categoria funcional (gramatical) ou lexical. O efeito destas classificações categóricas (ou tudo ou nada, ou lexical ou funcional) pode ser a falta de atenção para o fato de que a classe das preposições não é homogênea e que tanto a sintaxe como a semântica estão imbricadas na seleção e combinação de preposições. Atribuindo diferentes graus de gramaticalização às preposições, é possível observar como critérios fonético-fonológicos, morfológicos, semânticos, sintáticos e de frequência interagem e revelam sobre o funcionamento de preposições em certas populações de falantes (por exemplo, sujeitos agramáticos). As preposições mais gramaticalizadas podem assumir formas variadas, não têm um valor semântico específico, funcionam em diferentes posições sintáticas e são abundantes na língua. Entende-se que sujeitos afásicos com agramatismo recorram a preposições desse tipo enquanto estiverem em processo de reconstrução de linguagem.

A vantagem da descrição das preposições de acordo com seu grau de gramaticalização está no fato de que cada preposição é descrita em termos de 
forma, sentido, posição na sentença e frequência na língua. Para afásicos com agramatismo, questões de frequência parecem ser mais salientes que as de sentido ou função. Assim, as preposições mais gramaticalizadas estão mais propensas a aparecerem na fala de sujeitos afásicos com agramatismo, por serem mais frequentes na língua.

\section{Notas}

${ }^{1}$ Ver a gramática DUDEN (1998).

${ }^{2}$ Citado por Dahl (2001): Meillet, A. L'évolution des formes grammaticales. Scientia (Rivista di Scienza,12.6.) 1912. Longhim (2003) discute mais detidamente a noção de gramaticalização e a história do termo na Linguística.

${ }^{3}$ Citado por Dahl (2001): Gabelentz, Georg von der. Die Sprachwissenschaft: ihre Aufgaben, Methoden und bisherigen Ergebnisse. Leipzig, 1891.

${ }^{4}$ Citado por Dahl (2001): Geurts, Bart. Explaining grammaticalization (the standard way). Linguistics, 38, p. 781-798, 2000.

${ }^{5}$ Citado por Squartini (1998): The evolution of future meaning. In: Anna Giacalone Ramat - Onofrio Carruba - Giuliano Bernini, Papers from the 7 th. International conference on historical Linguistics, 109-122. Amsterdam/ Philadelphia: Benjamins, 1987.

${ }^{6}$ Citado por Squartini (1998): The evolution of grammar. Tense, aspect and modality in the languages of the world. Chicago/ London: The University of Chicago Press, 1994.

${ }^{7}$ Este fato contribui para que as listas de integrantes da classe das preposições apresentadas pelas gramáticas sejam diferentes de uma gramática para outra, como demonstra o estudo de Klaus (1999). Uma das gramáticas consultadas (VILELA; $\mathrm{KOCH}, 2001$ ) inclusive finalizava a lista de preposições com reticências, indicando que a classe dessas palavras não é finita. 


\section{Referências}

\section{Gramáticas consultadas}

ABREU, M. de; MOURA, G. de. Regência verbal. Editora Livraria Freitas Bastos S/A, 1957.

ALMEIDA, N. M. de. Gramática metódica da língua portuguesa. 22. ed. São Paulo: Edição Saraiva, 1969.

AZEVEDO FILHO, L. A. de. Gramática básica da língua portuguesa. Editora Fundo de Cultura, 1966.

BECHARA, E. Moderna gramática portuguesa. 11. ed. São Paulo: Companhia Editora Nacional, 1967.

BECHARA, E. Moderna gramática portuguesa. 37. ed. Rio de Janeiro: Editora Lucerna, 1999.

BRANDÃO, C. Sintaxe clássica portuguesa. Belo Horizonte: Imprensa da Universidade de Minas Gerais, 1963.

CEGALLA, D. P. Novíssima Gramática da língua portuguesa. São Paulo: Editora Nacional, 41. ed. 1998.

COUTINHO, I. de L. Pontos de gramática histórica. 7. ed. Rio de Janeiro: Ao Livro Técnico, 1979.

CUNHA, C. Gramática do português contemporâneo. Belo Horizonte: Editora Bernardo Álvares S.A., 1970.

CUNHA, C. Gramática de Base. Rio de Janeiro: FENAME, 1979.

DUDEN. Die Grammatik. Mannheim, Leipzig, Wien, Zürich: Dudenverlag, 1998.

GÓIS, C. Sintaxe de Regência. 8. ed. Rio de Janeiro: Livraria Francisco Alves, 1957.

LIMA, R. Gramática normativa da língua portuguesa. 36. ed. Rio de Janeiro: José Olympo, 1998.

LUFT, C. P. Moderna Gramática Brasileira. 6. ed. Rio de Janeiro: Editora Globo, 1985.

MELO, G. C. Gramática fundamental da língua portuguesa. 2. ed. Rio de Janeiro: Livraria Acadêmica, 1970.

NASCENTES, A. O problema da regência. 2. ed. Rio de Janeiro / São Paulo: Livraria Freitas Bastos S.A., 1960. 
NEVES, M. H. M. Gramática de usos do português. São Paulo: Editora UNESP, 2000.

SAMPAIO, B. Elementos de Gramática portuguesa. Campinas: Editora Livraria João Amêndola, 1953.

SAVIOLI, F.P. Gramática em 44 lições. 21. ed. São Paulo: Editora Ática, 1991.

SOUZA LIMA, M. P. Grammatica expositiva da língua portuguesa. São Paulo: Companhia Editora Nacional, 1937.

TÔRRES, A. A. Moderna gramática expositiva da língua portuguesa. 15.ed. Rio de Janeiro: Editôra Fundo de Cultura, 1963.

VILELA, M. \& KOCH, I. V. Gramática da Língua Portuguesa. Coimbra: Livraria Almeida, 2001.

\section{Demais textos consultados}

BASTIAANSE, R. Broca's aphasia: a syntactic and/or a morphological disorder? A case study. Brain and Language, v. 48, p. 1-32, 1995.

BAUDUSCH, S. Zur Semantik der Präpositionen. Zeitschrift für Phonetik, Sprachwissenschaft und Kommunikationsforschung, v. 37, n. 1, p. 89-93, 1984.

BERG, M. B. A natureza categorial da preposição. Revista de Estudos da Linguagem, v. 7, n. 1, p. 107-125, 1998.

BORSLEY, R. D.; JAWORSKA, E. On polish PPs. Linguistics, v. 27, n. 2, p. 245-57, 1989.

CORMACK, A.; BREHENY, R. Projections for functional categories. UCL Working Papers in Linguistics, v. 6, p. 35-63, 1994.

DAHL, Ö. The maturation of linguistic patterns. Stockholm. Manuscrito, 2001.

DI MEOLA, C. Präpositionale Rektionsalternation unter dem Gesichtspunkt der Grammatikalisierung: Das Prinzip der "maximalen Differenzierung”. In: CUYCKENS, H.; RADDEN, G. (Ed.). Perspectives on prepositions. Linguistische Arbeiten, 454, p. 101-131, 2002.

EMONDS, J. Projecting indirect objects. The Linguistic Review, v. 10, n. 3, p. 211-265, 1993.

FRIEDERICI, A. Syntactic and semantic processes in aphasic deficits: The availability of prepositions. Brain and Language, v. 15, p. 249-258, 1982. 
FRIEDERICI, A. Levels of processing and vocabulary types: Evidence from online comprehension in normals and agrammatics. Cognition, v. 19, p. 133-166, 1985. FRIEDERICI, A.; SCHÖNLE, P.; GARRETT, M. Syntactically versus semantically based computations: processing of prepositions in agrammatism. Cortex, v. 18, p. 525-534, 1982.

FRIEDERICI, A. D.; WESSELS, J. M. I.; EMMOREY, K.; BELLUGI, U. Sensitivity to inflectional morphology in aphasia: a real-time processing perspective. Brain and Language, v. 43, p. 47-64, 1992.

GONÇALVES, S. C. L.; LIMA-HERNANDES, M. C.; CASSEB-GALVÃO, V. (Org.). Introdução à gramaticalização. São Paulo: Parábola, 2007.

GORSKI, E. M. Níveis de integração de cláusulas para + infinitivo. Estudos Lingüísticos, v. 29, p. 88-102, 2000.

GRODZINSKY, Y. Syntactic representations in agrammatic aphasia: the case of prepositions. Language and Speech, v. 31, p. 115-134, 1988.

GUINDASTE, R. M. G. O agramatismo: um estudo de caso em português. 1996. Tese (Doutorado em Linguística) - IEL / Universidade Estadual de Campinas, Campinas, 1996.

HALLIWELL, J. F. Korean agrammatic production. Aphasiology, v. 14, p. 11871205, 2000.

HASPELMATH, M. Why is grammaticalization irreversible? Linguistics, v. 37, p. 1043-1068, 1999.

HOPPER, P. J.; TRAUGOTT, E. C. Grammaticalization. Cambridge: Cambridge University Press, 1993.

HUDSON, D. Syntax without functional categories. UCL Working Papers for Linguistics, v. 9, p. 253-281, 1997.

ILARI, R.; CASTILHO, A. T.; ALMEIDA, M. L. L.; KLEPPA, L.; BASSO, R. M. A Preposição. In: ILARI, R.; NEVES, M. H. M. (Org.). Gramática do português culto falado no Brasil.Campinas: Editora da Unicamp, 2009. v. 2, p. 623-804.

JESPERSEN, O. The Philosophy of Grammar. London: George Allen \& Unwin Ltd. [ 1924], 1948.

KLAUS, C. Grammatik der Präpositionen: Studien zur Grammatikographie. Linguistik International, v. 2, p. 225-228, 1999.

KLEPPA, L. Preposições ligadas a verbos na fala de uma criança em processo de aquisição de linguagem - ou - "Vamo de a pé no carro do vovô?" 2005. Dissertação (Mestrado) - IEL/UNICAMP, Campinas, 2005. 
KLEPPA, L. Preposições mais gramaticalizadas em dicionários escolares. Veredas On Line, v. 1, p. 112-128, 2008a.

KLEPPA, L. Preposições ligadas a verbos na fala de uma criança em processo de aquisição de linguagem e de dois sujeitos agramáticos em processo de reconstrução de linguagem - ou: “Eu e você? Diferente.”. 2008. Tese (Doutorado) - IEL/ UNICAMP, Campinas, 2008b.

LARSON, R. "Missing prepositions" and the analysis of English free clauses. Linguistic Inquiry, v. 18, n. 2, p. 239-267, 1987.

LEHMANN, C. Grammaticalization: synchronic variation and diachronic change. Lingua e Stile, v. 20, p. 303-318, 1985.

LONGHIM, R. S. A gramaticalização da perífrase conjuncional SÓ QUE. 2003. Tese (Doutorado em Linguística) - IEL, Universidade Estadual de Campinas, Campinas, 2003.

LONZI, L.; LUZZATTI, C. Omission of prepositions in agrammatism and the universal grammar constraint of recoverability. Brain and Language, v. 51, p. 129-132, 1995.

MEISEL, J. M. Prepositions in object and adverbial constructions. Lingua, v. 31, n. 2+3, p. 213-236, 1973.

MENN, L.; OBLER, L. K. Agrammatic aphasia: A cross-language narrative sourcebook. Amsterdam/ Philadelphia: John Benjamins Publishing Company, 1990.

NESPOULOUS, J-L.; DORDAIN, D.; PERRON, C.; SKA, B.; BUB, D.; CAPLAN, D.; MEHLER, J.; LECOURS, A. R. Agrammatism in sentence production without comprehension deficits: reduced availability of syntactic structures and/ or of grammatical morphemes? A case study. Brain and Language, v. 33, p. 273-296, 1988.

NILLIPOUR, R. Agrammatic language: two cases from Persian. Aphasiology, v. 14, p. 1205-1242, 2000.

OUHALLA, J. Functional categories, Agrammatism and Language Acquisition. Linguistische Berichte, v. 143, p. 3-37, 1993.

POGGIO, R. M. G. F. Gramaticalização de preposições documentadas na edição crítica “A mais antiga versão dos Diálogos de São Gregório”. Estudos Linguísticos, v. 29, p. 393-398, 2000.

POGGIO, R. M. G. F. Processos de gramaticalização de preposições do latim ao português. Uma abordagem funcionalista. Salvador: EDUFBA, 2002. 
RAPOSO, E.P. Categorias funcionais na gramática gerativa. Delta, v. 9, n. 2, p. 237-275, 1993.

RAUH, G. Präpositionen: eine geschlossene Klasse? Die Neueren Sprachen, v. 89, p. 476-489, 1990.

RAUH, G. Grammatische Kategorien. In: Theorie des Lexikons: Arbeiten des Sonderforschungsberreichs, 282. Wuppertal / Köln: Universität Wuppertal \& Universität Köln. 1993.

RAUH, G. Prepositions, features and projections. In: CUYCKENS, H.; RADDEN, G. (Ed.). Perspectives on prepositions. Linguistische Arbeiten, v. 454, p. 3-25, 2002.

SILVA, M. C. P. O emprego das preposições em francês. Estudos Lingüísticos, v. 23, p. 1358-1364, 1999.

SQUARTINI, M. Verbal periphrases in Romance: aspect, actionality and grammaticalization. Berlin / New York: Mouton de Gruyter, 1998.

STENZEL, A. Development of prepositional case in a bilingual child. Linguistics, v. 34, n. 5, p. 1029-1059, 1996.

STOLZ, T. Flexion und Adpositionen, flektierte Adpositionen, adpositionelle Flexion. Zeitschrift für Phonetik, Sprachwissenschaft und Kommunikationsforschung, v. 43, n. 3, p. 334-354, 1990.

TESAK, J. Dutch telegraphese. Linguistics, v. 32, p. 325-344, 1994.

TESAK, J.; DITTMANN, J. Telegraphic style in normals and aphasics. Linguistics, v. 29, p. 1111-1137, 1991.

WUNDERLICH, D. How do prepositional phrases fit into compositional syntax and semantics? Linguistics, v. 29, n. 4, p. 591-623, 1991.

ZWARTS, J. Lexical and functional properties of prepositions. In: HAUMANN, D.; SCHIERHOLZ, S. J. (Ed.). Lexikalische und grammatische Eigenschaften präpositionaler Elemente. Linguistische Arbeiten, v. 371, p. 1-19, 1997. 